\title{
Birth Order Significantly Affects the Mental Health Emotionally As Well As Psychologically
}

\author{
Rupali Chandola $^{1}$, S. C. Tiwari ${ }^{2}$
}

\section{ABSTRACT}

Background: Birth order, defined as an individual's rank by age among siblings. Most of the fascination has focused on the possible role of birth order in shaping personality and behavior. Components of family structure during formative years that reflect emotional and psychological status, coping and relating styles of mature individuals. The researcher attempted to determine whether an individual's place in the family, known as "birth order", affected that person's emotional maturity and mental health. Methods: Study conducted on 40 participants of either sex 20 was psychiatrically ill and another 20 normal control. They were held from Pt. Deendayal Upadhyay joint hospital, district Moradabad, U. P, India. GHQ-12 negative participants from the community formed the normal group age ranging between young adulthood (20-30) years. Emotional maturity scale was administered on all the participants included in this study. Demographic data included gender, domicile, religion; education and list of the participant's siblings i.e. birth order of the participants. Result: Analysis of the data indicated 'oldest' born psychiatric patients extremely unstable on the level of emotionality rather than other group. Conclusion: The place of the individual within the family, the first social structure encountered, has been suggested as a contributing factor in shaping human personalities as well as emotional development.

Keywords: Birth Order, Mental Health, Emotional Maturity.

Birth sequence defined as an individual's rank by age among siblings. Most of the fascination has focused on the possible role of birth order in shaping personality and behavior. Many decades ago, Alfred Adler, a contemporary of Sigmund Freud and Carl Jung, suggested that personality traits are related to a person's ordinal position within the family. He claimed that oldest, once the sole focus of parental attention and resources would be resentful when attention

\footnotetext{
${ }^{1}$ Ph.D Scholar, Department of Psychology, Kumaun University S.S.J.Campus, Almora, Uttrakhand, India

${ }^{2}$ Professor and Head, Department of Geriatric Mental Health, King George's Medical University, U.P. Lucknow, India

*Responding Author

(C) 2016, R Chandola, S Tiwari; licensee IJIP. This is an Open Access Research distributed under the terms of the Creative Commons Attribution License (http://creativecommons.org/licenses/by/2.0), which permits unrestricted use, distribution, and reproduction in any Medium, provided the original work is properly cited.
} 


\section{Birth Order Significantly Affects the Mental Health Emotionally As Well As Psychologically}

shifted upon the birth of the next child, and that this would result in neuroticism and possible substance abuse. In his view, youngest would be spoiled and emotionally immature, while middle children would be the most stable, as they never experienced dethronement or being spoiled. Family roles govern the perceived expectations and responsibilities placed on children by parents and siblings. Children's perception of their place in the family constellation influences how they feel about themselves, and how they interact with others [1].Components of family structure during formative years that reflect emotional and psychological status, coping and relating styles of mature individuals[2].Although many genetic and environmental factors contribute to differences between siblings, some differences in behaviour of siblings have been attributed to the effects of birth order[]ㅡ, an individual's rank by age among siblings [프. The place of the individual within the family, the first social structure encountered, has been suggested as a contributing factor in shaping human personalities [4] , and influencing interactions in subsequent social structures. Although the view that birth order is the sole predictor of development across the lifespan has never been widely accepted, an individual's birth order is a possible influence on relationships with parents and siblings, which may affect personality formation and social behaviour across the lifespan [ㄷ]. Socialization differences experienced by individuals due to their ordinal position of birth may result in overt personality and behaviour differences. In the absence of siblings, first born i.e. oldest tend to be socialized by adults, whereas later born are exposed to the socializing influences of older siblings [3]]. Adults socialized as first born, are sometimes theorized to be more achievement oriented, while their younger siblings are often believed to be more successful in social endeavors, experience greater enjoyment during risk taking behaviour and be more independent of authority [3]]. It is acknowledged that such characterizations are general and imprecise at best []]

Birth order research has always been controversial. One of the first modern psychologists to address the influence of birth order on personality development across the lifespan was Alfred Adler in the 1920's. Since his description of the effects of ordinal position of birth on personality [3], many theories have been suggested to explain apparent differences. These include dethronement of the first born, parental anxiety, economic factors, intrauterine conditions [3] and historical cohort effects. Much of the debate of possible effects of birth order has focused on intellectual abilities, academic achievement [ㅁ,] $]$, economic resources[] $]$ and family intellectual environment[]].

Knowing these entire things we can say that role of family, social environment, interaction of the child with other people, their parents and siblings built their personality, emotional maturity as well as psychological development. Child mirror image and parental attitude toward child, is the most important thing to grow the child in a healthy manner. 
Keeping these views in consideration this study was planed titled as "Birth order significantly affects the mental health emotionally as well as psychologically" the objective and hypothesis were as follows:

\section{Objective}

$\checkmark$ The first objective of this study was to find out the difference between mental health and emotional maturity of male participants.

$\checkmark$ The second objective of this study was to find out the difference between mental health and emotional maturity of female participants.

$\checkmark$ The third objective of this study was to find out the difference between birth order and mental health.

$\checkmark$ The fourth objective of this study was to find out the difference between birth order and emotional maturity.

\section{Hypotheses}

$>\quad$ There will be no difference in emotional maturity of normal and psychiatric male.

$>\quad$ There will be no difference in emotional maturity of normal and psychiatric female

$>\quad$ There will be no difference in birth order and mental health.

$>\quad$ There will be no difference in birth order and emotional maturity.

\section{METHOD}

\section{Participants:}

20 normal and 20 psychiatric patients participated in the research, ranging from young adulthood (20-30) year in age. Participants were chosen at Pt Deendayal upadhyay joint hospital; district Moradabad, U.P, India. GHQ-12 negative participants from the community formed the normal group. Mean age of normal group was found to be 26.6 year with standard deviation of 2.45 years and mean age of psychiatric group was found to be 26.12 with standard deviation of 1.92 years. 30\% of the sample reported being 'oldest'; $20 \%$ of the sample reported being 'middle'; $25 \%$ of the sample reported being the 'youngest' in their families; and $25 \%$ of the sample reported being ‘only' children.

\section{Materials:}

General Health Questionnaire-12 (GHQ-12): The 12-Item General Health Questionnaire [9]] is the most extensively used screening instrument for common mental disorders, in addition to being a more general measure of psychiatric well-being.

Emotional maturity scale (EMS): It is constructed by [10] and deals with five factors of emotional maturity. Emotional Maturity scale has a total of 48 items under the five categories, ' Emotional Stability', 'Emotional Progression', Social adjustment', personality Interaction' and 'Dependence'. EMS is a self reporting Five Point Scale. Items of the scale are in question form demanding information for each in either of the five options 'very much', 'much', 'undecided' 
'probably' 'never 'the higher the score on the scale greater the degree of the emotional immaturity and vice-versa. Demographic data included gender, domicile, religion; education and list of the participant's siblings i.e. birth order of the participants.

\section{Procedure:}

As mentioned before the study was distributed in two different settings i.e. Hospital set up and other was community. Diagnosed case of psychiatric disorder selected purposively from the OPD of Pt Deendayal upadhyay joint hospital,district Moradabad,U.P,India.GHQ-12 negative participants from the community formed the normal group. For psychiatric data interview conducted in the separate room associated with the ward to maintain confidentiality $22.5 \%$ participant's neurotic and 27.5\%were psychotic and 50\% normal healthy control. Uncooperative subjects, having problem in speech and communication which can impede the interview were excluded from the study. Emotional maturity scale (EMS) with demographic detail administered on all the participants included in the study.

Keeping view the main objectives of the present study chi-square, fisher exact test \& t- test was employed to see the difference between normal and psychiatric group, level of emotionality according to their birth sequence.

\section{RESULTS}

The result of the present study has been given below and consecutively discussed.

Table-1 demographic characteristics of the participants there was two groups included in this study. Group one was normal and another was psychiatric.(50\%) male and (50\%) female in both groups. (70\%) participants belong from rural area suffering with psychiatric illness. On the basis of religion (75\%) participants were Hindu (55\%) normal group up to graduate (50\%) psychiatric population up to $8^{\text {th }}$.

Table 1 represents the socio-demographic detail of the participants

\begin{tabular}{|cccc|}
\hline Category & $\begin{array}{c}\text { Demographic } \\
\text { detail }\end{array}$ & Normal(N=20) & Psychiatric(N=20) \\
\hline Gender & Male & $10(50 \%)$ & $10(50 \%)$ \\
& Female & $10(50 \%)$ & $10(50 \%)$ \\
Domicile & Urban & $11(55 \%)$ & $3(15 \%)$ \\
& Semi urban & $4(20 \%)$ & $3(15 \%)$ \\
\multirow{5}{*}{ Religion } & Rural & $5(25 \%)$ & $14(70 \%)$ \\
& Hindu & $8(40 \%)$ & $15(75 \%)$ \\
& Muslin & $9(45 \%)$ & $4(20 \%)$ \\
& Christian & $3(15 \%)$ & $1(5 \%)$ \\
& Up to 8 ${ }^{\text {th }}$ & $2(10 \%)$ & $10(50 \%)$ \\
& Up to 12 $2^{\text {th }}$ & $5(25 \%)$ & $6(30 \%)$ \\
& Up to Graduation & $11(55 \%)$ & $4(20 \%)$ \\
\hline
\end{tabular}


Comparison of emotional maturity normal and psychiatric group regarding their score each participants on emotional maturity scale (EMS) were categorized in extremely stable (50-80), moderate stable (81-88), unstable (89-106) and extremely unstable (107-240) and compared in (table 4).

Table-2 Mean and SD of normal and psychiatric male participants on the basis of emotional maturity scale

\begin{tabular}{|lccccc|}
\hline Areas of Emotionality & Group & $\mathbf{N}$ & Mean & S.D. & t- value \\
\hline 1 Emotional stability & Normal male & 10 & 66.9 & 12.12 & $6.30 * \mathrm{Df}=38$ \\
& Psychiatric male & 10 & 93.4 & 14.38 & $\mathrm{P}<0.01$ \\
2 Emotional Progression & Normal male & 10 & 69.9 & 9.99 & $4.39 * \mathrm{Df}=38$ \\
& Psychiatric male & 10 & 89.6 & 17.39 & $\mathrm{P}<0.01$ \\
\multirow{3}{*}{ Social Adjustment } & Normal male & 10 & 80.5 & 13.53 & $3.18 * \mathrm{Df}=38$ \\
& Psychiatric male & 10 & 119.5 & 53.06 & $\mathrm{P}<0.01$ \\
\multirow{4}{*}{ 4 Personality Integration } & Normal male & 10 & 69.3 & 13.24 & $4.70 * \mathrm{Df}=38$ \\
& Psychiatric male & 10 & 120.7 & 46.98 & $\mathrm{P}<0.01$ \\
& Normal male & 10 & 62.0 & 9.89 & $9.19 * \mathrm{Df}=38$ \\
& Psychiatric male & 10 & 135.6 & 34.42 & $\mathrm{P}<0.01$ \\
\hline
\end{tabular}

*Significant at $\mathrm{p}<0.01$ level

Table-2 reveal that the first hypothesis, regarding the emotional maturity normal and psychiatric male shows significant difference in the mean score $(\mathrm{p}<0.01)$ on all areas of emotional maturity. The area of 'Independence' there was highly significant difference was found in the mean score $(p<0.01)$ which indicate the area of 'independency' psychiatric male was extremely unstable in comparison to other group. The mean score of 'social adjustment' psychiatric male found to be unstable whenever normal male found to be extremely stable in the area of 'social adjustment' of emotional maturity.

Table-3Mean and SD of normal and psychiatric female participants on the basis of emotional maturity scale

\begin{tabular}{|c|c|c|c|c|c|}
\hline Areas of Emotionality & Group & $\mathbf{N}$ & Mean & S.D. & t- value \\
\hline \multirow[t]{2}{*}{1 Emotional stability } & Normal female & 10 & 68.3 & 3.81 & $3.06 * \mathrm{Df}=38$ \\
\hline & Psychiatric female & 10 & 84.4 & 19.03 & $\mathrm{P}<0.01$ \\
\hline \multirow[t]{2}{*}{2 Emotional Progression } & Normal female & 10 & 67.7 & 14.21 & $4.05 * \mathrm{Df}=38$ \\
\hline & Psychiatric female & 10 & 108.1 & 42.22 & $\mathrm{P}<0.01$ \\
\hline \multirow[t]{2}{*}{3 Social Adjustment } & Normal female & 10 & 81.4 & 13.77 & $2.09 * * \mathrm{Df}=38$ \\
\hline & Psychiatric female & 10 & 91.1 & 15.48 & $\mathrm{P}<0.05$ \\
\hline \multirow[t]{2}{*}{4 Personality Integration } & Normal female & 10 & 70.31 & 12.44 & $5.59 * \mathrm{Df}=38$ \\
\hline & Psychiatric female & 10 & 95.7 & 16.02 & $\mathrm{P}<0.01$ \\
\hline \multirow[t]{2}{*}{5 Independence } & Normal female & 10 & 68.5 & 13.64 & $1.59 * * \mathrm{Df}=38$ \\
\hline & Psychiatric female & 10 & 79.4 & 27.45 & $\mathrm{P}<0.05$ \\
\hline
\end{tabular}

*Significant at $\mathrm{p}<0.01$ level **Significant at $\mathrm{p}<0.05$ level 


\section{Birth Order Significantly Affects the Mental Health Emotionally As Well As Psychologically}

Table-3 reveal that the third hypothesis, regarding the emotional maturity normal and psychiatric female shows significant difference in the mean score $(p<0.01 \& p<0.05)$ on all areas of emotional maturity between normal and psychiatric female. The area of 'Emotional progression' the mean score indicate that psychiatric female extremely unstable in comparison of normal female. Almost similarity has seen between the area of 'social adjustment' of emotional maturity which indicate normal female moderate stable and psychiatric female unstable in 'social adjustment.

Table 4: Comparison of Health Status of two genders according to their birth sequence

\begin{tabular}{|c|c|c|c|c|c|c|}
\hline \multirow{2}{*}{$\begin{array}{c}\text { Birth } \\
\text { sequence }\end{array}$} & \multirow[t]{2}{*}{ Gender } & \multirow{2}{*}{$\begin{array}{c}\text { Normal } \\
\text { Group }=20\end{array}$} & \multicolumn{3}{|c|}{ Psychiatric group $\mathrm{N}=20$} & \multirow{2}{*}{$\begin{array}{c}\text { Fisher's exact } \\
\text { value/ } \mathbf{X}^{2}\end{array}$} \\
\hline & & & Neurotic & Psychotic & Total Psychiatric & \\
\hline \multirow[t]{2}{*}{ Oldest } & Male & $0(0 \%)$ & $2(33.33 \%)$ & $4(66.66 \%)$ & $6(30 \%)$ & $0.00 * / 8.57 * *$ \\
\hline & Female & $5(83.33 \%)$ & 1(16.66\%) & $0(0 \%)$ & $1(5 \%)$ & \\
\hline \multirow[t]{2}{*}{ Youngest } & Male & $4(57.14 \%)$ & $1(14.28 \%)$ & $2(28.57 \%)$ & $3(15 \%)$ & $0.58 / 0.47$ \\
\hline & Female & 1(33.33\%) & $0(0 \%)$ & $2(66.66 \%)$ & $2(10 \%)$ & Non significant \\
\hline \multirow[t]{2}{*}{ Middle } & Male & 2(33.33\%) & $2(33.33 \%)$ & 2(33.33\%) & $4(20 \%)$ & 0.99/0.17 \\
\hline & Female & 1(50\%) & $1(50 \%)$ & $0(0 \%)$ & $1(5 \%)$ & Non significant \\
\hline \multirow[t]{2}{*}{ Only } & Male & $6(85.71 \%)$ & $0(0 \%)$ & $0(0 \%)$ & $0(0 \%)$ & $0.03 * / 6.42 * *$ \\
\hline & Female & 1(25\%) & $2(50 \%)$ & $1(25 \%)$ & $3(15 \%)$ & \\
\hline
\end{tabular}

**Significant at $\mathrm{p}<0.01$ level * Fisher exact value

Table 4 reveal that the third hypothesis, regarding the birth order and mental health it was found that 'oldest' male had high psychiatric morbidity (30\%) then female (5\%), the difference is statistically at $(\mathrm{p}<0.01)$. Insignificant difference was found on 'Youngest' and 'middle' born child on their mental condition. 'Only' born female had psychiatric morbidity (15\%) then male (0\%).

Table 5: Level of emotional maturity according to the birth sequence of normal and psychiatric group

\begin{tabular}{|c|c|c|c|c|c|c|}
\hline \multirow{2}{*}{$\begin{array}{c}\text { Birth } \\
\text { Sequence }\end{array}$} & \multirow[t]{2}{*}{ Group } & \multicolumn{4}{|c|}{ Level of emotionality } & \multirow{2}{*}{$\begin{array}{c}\text { Fisher's exact } \\
\text { value }\end{array}$} \\
\hline & & $\begin{array}{c}\text { Extremely } \\
\text { stable }\end{array}$ & $\begin{array}{c}\text { Moderate } \\
\text { stable }\end{array}$ & Unstable & $\begin{array}{c}\text { Extremely } \\
\text { unstable }\end{array}$ & \\
\hline \multirow[t]{2}{*}{ Oldest } & Normal & $1(5 \%)$ & $2(10 \%)$ & $2(10 \%)$ & $0(0 \%)$ & $0.04^{*}$ \\
\hline & Psychiatric & $0(0 \%)$ & $1(5 \%)$ & $1(5 \%)$ & $5(25 \%)$ & \\
\hline \multirow[t]{2}{*}{ Youngest } & Normal & $2(10 \%)$ & $3(15 \%)$ & $0(0 \%)$ & $0(0 \%)$ & $0.01 *$ \\
\hline & Psychiatric & $1(5 \%)$ & $0(0 \%)$ & $1(5 \% 0$ & $3(15 \%)$ & \\
\hline \multirow[t]{2}{*}{ Middle } & Normal & $1(5 \%)$ & $1(5 \%)$ & $0(0 \%)$ & $1(5 \%)$ & 0.46 \\
\hline & Psychiatric & $0(0 \%)$ & $1(5 \%)$ & $2(10 \%)$ & $2(10 \%)$ & Non significant \\
\hline \multirow[t]{2}{*}{ Only } & Normal & $1(5 \%)$ & $5(5 \%)$ & $0(0 \%)$ & $1(5 \%)$ & $0.03^{*}$ \\
\hline & Psychiatric & $0(0 \%)$ & $0(0 \%)$ & $1(5 \%)$ & $2(10 \%)$ & \\
\hline
\end{tabular}

* Fisher exact value

The fifth and final hypothesis was also tested using a fisher exacts value. This hypothesis stated that 'oldest' born psychiatric patients (25\%) extremely unstable on the level of emotionality; the

(C) The International Journal of Indian Psychology, ISSN 2348-5396 (e)| ISSN: 2349-3429 (p) | 101 
difference is statistically significant. 'Youngest' born psychiatric patients (15\%) extremely unstable on the level of emotionality in comparison to other group, the difference is statistically significant. 'Middle' born participants of both group had no significant difference on the level of emotionality. 'Only' born psychiatric patients had high (10\%) extremely unstable on the basis of emotionality. Significant difference was found on 'oldest' 'youngest' \& 'only' children on their emotional maturity. (table-5)

The results indicate that the original hypothesis rejected in this research.

\section{DISCUSSION}

The study was conducted to explore the birth sequence significantly affects the mental health emotionally as well as psychologically of normal and psychiatric group (GHQ-12 negative participants from the community formed the normal group Diagnosed case of psychiatric disorder selected purposively from the OPD of Pt Deendayal upadhyay joint hospital,district Moradabad, U.P . Finding reveal that there was significant difference was found in the mean score $(p<0.01)$ on all areas of emotional maturity between normal and psychiatric male. According to the interpretation of score the mean score of psychiatric group highest in the area of 'independence' which shows these group are extremely unstable in emotional maturity mean of the score represent that psychiatric group never like to show any habitual reliance upon another person in making his decisions or crying out difficult actions, whereas are dependent person shows parasitic dependence or other is ego tic and lacks objective interest rather than other group. Significant difference was found in the mean score $(\mathrm{p}<0.01 \& \mathrm{p}<0.05)$ on all areas of emotional maturity between normal and psychiatric female. The mean score of emotional progression of female psychiatric group is high which shows that female psychiatric group is extremely unstable they felt feeling of inferiority, restlessness, hostile, aggression and self centered in the society rather than other group. In order to find out the birth order 'oldest' born male had high psychiatric morbidity (30\%) then female (5\%), the difference is statistically at $(\mathrm{p}<0.01)$. Similar study reported that many genetic and environmental factors contribute to differences between siblings; some differences in behaviour of siblings have been attributed to the effects of birth order [3] 'oldest' born psychiatric patients (25\%) extremely unstable on the level of emotionality; the difference is statistically significant .Some study reported that Components of family structure during formative years that reflect emotional and affiliative ties are implicated in the psychological status, coping and relating styles of mature individuals[2]. 'Youngest' born psychiatric patients (15\%) extremely unstable on the level of emotionality in comparison to normal control, the difference is statistically significant. Individual's birth order is a possible influence on relationships with parents and siblings, which may affect personality formation and social behaviour across the lifespan [5].

There is need to study those person who are normal having different birth order and share common emotional immaturity like extremely unstable or unstable with psychiatric group and later develop any kind of mental illness longitudinally.

(C) The International Journal of Indian Psychology, ISSN 2348-5396 (e)| ISSN: 2349-3429 (p) | 102 


\section{CONCLUSION}

Finding in general reveals that significant difference was found in on all areas of emotional maturity between normal and psychiatric group. 'Oldest' born male had high psychiatric morbidity rather than other group and result also shows that 'oldest' born mentally ill participants extremely unstable on the level of emotionality. Most of the time due to family environment, social pressure parental attitude and their comparison between their children affect upon overall growth of the child. 'Only' child over protected by their parents therefore they were socially rigid and their confidence level found to be low.

Because birth order has been argued as a factor in personality development, many research studies have been done examining birth order. However, because much of this research is either inconclusive or contradictory, more is needed to support or negate current research and theories.

\section{Acknowledgement}

Authors are grateful to the Director and staff of Pt Deendayal upadhyay joint hospital, district Moradabad, U.P, India for permission of data collection and study subjects \& for their cooperativeness.

\section{Conflict of Interest: None}

\section{REFERENCES}

[1] Nims, D.R. (1998).Searching for self: a theoretical model for applying family Systems to adolescent group work. Journal for Specialists in Group Work, 23, 133-144...

[2] Fullerton, C.S., Ursano, R.J., Wetzler, H.P., \& Slusarcick, A.(1989). Birth order, Psychological well-being and social supports in young adults. The Journal of Nervous and Mental Disease, 177, 556-559.

[3] Claxton, R.P.(1994).Empirical relationships between birth order and two types of Parental feedback. Psychological Record, 44, 475-487.

[4] Gould, S.J.(1997).Dolly's fashion and Louis's passion. Natural History,106, 18-24.

[5] Buckley, G.J.(1998).Adler's birth order traits.

[6] Bohmer, P., \& Sitton, S. (1993).The influence or birth order and family size on notable American women's selection of careers. Psychological Record, 43, 375-380.

[7] Morjoribanks, K.(1997).Ordinal position, family environment, and status attainment among Australian young adults. The Journal of Social Psychology, 137, 398-399.

[8] Travis, R.,\& Kohli, V.(1995).The birth order factor: ordinal position, social strata, and Educational achievement. The Journal of Social Psychology, 135, 499-507.

[9] Singh,Y \& Bhargava,M (2006).Emotional Maturity Scale; National psychological corporation, Agra. 
[10] Jacob, K.S., Bhugra, D., Mann, A.H. (1997) The validation of the 12-item General Health Questionnaire among ethnic Indian women living in the United Kingdom. Psychological Medicine, 27(5): 1215-17.

How to cite this article: Chandola, S Tiwari (2016), Birth Order Significantly Affects the Mental Health Emotionally As Well As Psychologically, International Journal of Indian Psychology, Volume 3, Issue 4, No. 67, ISSN:2348-5396 (e), ISSN:2349-3429 (p), DIP:18.01.184/20160304, ISBN:978-1-365-39397-6 